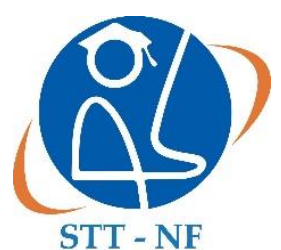

STT - NF
Jurnal Teknologi Terpadu

Journal of Integrated Technology

https://journal.nurulfikri.ac.id/index.php/JTT

ISSN : 2477-0043 ISSN ONLINE : 2460-7908

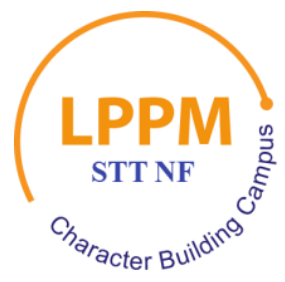

\title{
OPTIMASI HYBRID INVISIBLE WATERMARKING RDWT-DCT-SVD MENGGUNAKAN ALGORITMA PSO PADA CITRA DIGITAL
}

\author{
Oki Januar Insani, Nendi, Indra Nugraha Abdullah \\ Program Studi Magister Ilmu Komputer, Program Pascasarjana, Universitas Budi Luhur \\ Jakarta Selatan, DKI Jakarta, Indonesia \\ okijanuarmals@gmail.com,nendijuve@gmail.com, indra.nuab@gmail.com
}

\begin{abstract}
It is now so easy in this digital age to duplicating and distributing any information, particularly in image data which makes some people using it for negative purposes because by using false image information, indeed violates intellectual property rights from data ownership. The Watermarking method is one of many approaches to copyright protection. There are several ways to apply watermarking, one of them is a hybrid invisible watermark. Research that has been done by Anu Bajaj in 2013 which combining RDWT-DCT-SVD techniques by proving the results of its efficiency with PSNR values for different attacks. However, on its research advice told watermarking hybrid is not safe, so on the next research, it is recommended to increase the security in the form of optimization in terms of inserting information into the input image, in order to improve PSNR assessment scheme which is sufficiently safe and higher. The goal of this research is the author adding the PSO algorithm to be combined with its hybrid technique with the intention of providing security in terms of inserting and giving improvement on the PSNR scheme. By this analysis result, examination and comparison can be concluded that hybrid invisible watermarking, RDWT-DCT-SVD with PSO optimizing have significantly higher results that have means $50 \mathrm{~dB}$, so this has better imperceptibility quality..
\end{abstract}

Keywords: PSO, PSO watermarking, invisible watermark, hybrid watermarking, RDWT, DCT, SVD.

\begin{abstract}
Abstrak
Begitu mudahnya di era digital ini dalam menduplikasi dan mendistribusi berbagai macam informasi khususnya pada data citra yang membuat sebagian orang menggunakan untuk keperluan yang negatif karena dengan melakukan penyimpangan informasi citra tentu melanggar hak cipta intelektual dari kepemilikan data. Metode watermarking merupakan salah satu pendekatan untuk perlindungan hak cipta. Dalam penerapan watermark ada beberapa cara, salah satunya adalah hybrid invisible watermark. Penelitian oleh Anu Bajaj pada tahun 2013 yang menggabungan teknik RDWT-DCT-SVD dengan membuktikan hasil efisiensinya dengan nilai PSNR terhadap serangan yang berbeda. Namun pada saran penelitian tersebut menyebutkan bahwa kombinasi hybrid watermarking tidak aman, sehingga pada penelitian selanjutnya disarankan harus menambahkan keamanan berupa optimasi dari segi penyisipan informasi ke dalam citra masukannya, agar dapat meningkatkan skema penilaian PSNR yang aman dan lebih tinggi. Tujuan dari penelitian ini adalah penulis menambahkan algoritma PSO untuk dikombinasi dengan metode hybrid tersebut dengan tujuan dapat menghasilkan keamanan dari segi penyisipan dan menghasilkan peningkatan dari skema PSNR. Berdasarkan hasil analisis, pengujian dan komparasi dapat disimpulkan bahwa hybrid invisible watermarking RDWT-DCT-SVD dengan optimasi PSO memiliki hasil yang signifikan lebih tinggi dengan rata-rata $50 \mathrm{~dB}$ sehingga memiliki kualitas imperceptibility yang lebih baik.
\end{abstract}

Kata kunci: PSO, PSO watermarking, invisible watermark, hybrid watermarking, RDWT, DCT, SVD. 


\section{PENDAHULUAN}

Dengan semakin berkembangnya teknologi IoT, machine learning dan BigData di era saat ini. Keamanan data juga harus berjalan linier seiring kemajuan tersebut, pengolahan citra merupakan salah satu bidang teknologi keamanan data yang berkembang. Pengolahan citra memerlukan teknikteknik keamanan sehingga dapat diimplementasikan pada citra dalam memberi perlindungan hak cipta pada suatu citra yang dimilikinya. Otenfikasi dan perlindungan hak cipta dari citra akan dapat digunakan sebagai proses identifikasi penyimpangan seperti duplikasi citra tanpa izin, pembajakan, manipulasi data dari sebuah isi citra dan distribusi secara ilegal dalam bentuk yang menyerupai dengan citra aslinya, hal tersebut tentu saja melanggar hak cipta intelektual pemilik data. Perlindungan hak cipta memiliki beberapa pendekatan salah satunya pendekatan yang dikenal dengan watermarking digital, yaitu penyisipan media yang tak terlihat yang dalam citra. Nantinya citra tersebut dapat dilihat apakah data yang otentik/resmi atau data tersebut telah dimanfaatkankan pihak lain tanpa izin. Pemakaian watermarking harus memenuhi kriteria penilaian salah satunya yaitu imperceptibility (keberadaan citra watermark). Teknik watermarking dapat dibangun secara hybrid invisble, yaitu penyisipan yang tak terlihat oleh kasat mata. Hasil proses penyisipan ini didapat menunjukkan citra watermarking yang yang telah disisipi masih dapat dilihat dan tidak adanya perubahan citra secara signifikan yang dilihat oleh mata.

Pada penelitian hybrid invisible watermarking ini beberapa sudah ada yang menganalisa, metode populer dan keterbaruan yang digunakan saat ini adalah kombinasi RDWT-DCT-SVD. Metode RDWT (Redundant Discrete Wavelet Transform), DCT (Discrete Cosine Transform) dan SVD (Singular Value Decomposition) merupakan cara invisible watermark dengan kualitas yang kuat sehingga menghasilkan imperceptibility yang tinggi.

Tentunya kombinasi hybrid tersebut sudah dikomparasi dengan metode lain yang digunakan untuk watermarking. Metode RDWT-DCT-SVD memiliki transformasi dan fungsi yang berbeda-beda, RDWT biasanya digunakan untuk transformasi citra, kompresi dan dapat diterapkan pada bidang steganografi. Dengan proses transformasi RDWT, citra akan didekomposisi menjadi 4 subbands yang memiliki frekuensi yang berbeda. Pada metode DCT konsep yang digunakan adalah merubah koefisien
DCT menjadi koefisien baru dengan cara menggunakan transformasi dari gelombang cosinus diskrit. Lalu SVD merupakan teknik yang digunakan dalam menyisipkan watermark ke dalam citra dengan cara merubah nilai dari matriksnya.

Beberapa referensi yang membahas hybrid RDWTDCT-SVD ini di antaranya adalah penelitian Anu Bajaj yang menggabungkan teknik RDWT-DCT dan SVD dengan membuktikan hasil efisiensinya dengan nilai PSNR dan NCC terhadap serangan yang berbeda [1]. Penelitian selanjutnya yaitu hybrid RDWT-DCT dan SVD dengan Arnold Transform, bertujuan untuk memberi ketahanan lebih pada citra watermark-nya, sehingga mengghasilkan PSNR yang tinggi. Hasil penelitian tersebut menghasilkan skema PSNR yang tinggi diatas $54 \mathrm{~dB}$ [2]. Penelitian selanjutnya, mengkombinasi RDWT-DCT-SVD dalam watermarking citra digital yang berwarna dengan parameter penilaian PSNR dengan hasil penelitian bahwa PSNR diatas 40dB [3].

Metode hybrid invisible watermarking ini dapat dikombinasikan lagi dengan beberapa metode, salah satunya metode optimasi yaitu menggunakan algoritma PSO. Algoritma optimasi PSO adalah pencarian solusi terbaik dan konsep kerjanya yaitu membangkitkan populasi partikel secara acak atau random menggunakan batasan nilai terbesar dan terkecil. Alasan penulis mengusulkan optimasi PSO dan metode hybrid watermarking RDWT-DCT-SVD ini mengacu pada referensi-referensi bahwa algoritma PSO pernah diteliti khususnya di bidang watermarking dengan hasil yang baik.

Penelitian watermarking menggunakan algoritma PSO diantaranya adalah skema hybrid watermarking dengan menggunakan konsep Singular Value Decomposition (SVD) dengan optimasi PSO dengan hasil penelitian kualitas citra yang bagus terhadap imperceptibility dan robustness [4]. Penelitian selanjutnya, mengoptimasi koefisien transformasi DWT-DCT dengan proses generate random PSO pada saat menanamkan watermark dan hasil penelitiann kualitas citra lebih baik menggunakan PSO karena pada tekniknya memilih koefisien untuk kunci rahasia watermark-nya [5].

Berdasarkan dari referensi-referensi di atas, hybrid watermarking RDWT-DCT-SVD merupakan metode yang kuat akan ketahanan dan kualitas citra untuk menyisipkan citra watermark, akan tetapi pada saran penelitian Anu Bajaj [1] menyebutkan bahwa 
kombinasi hybrid watermarking kurang aman, sehingga pada penelitian selenjutnya disarankan harus menambahkan keamanan dari segi penyisipan informasi ke dalam citra masukannya, agar dapat meningkatkan skema penilaian PSNR yang aman dan lebih tinggi. Maka pada penelitian ini penulis akan menjawab saran penelitian tersebut dengan menambahkan keamanan dari segi penyisipan dengan cara optimasi metode hybrid RDWT-DCT-SVD. Algoritma optimasi yang cocok berdasarkan referensireferensi dalam pembangunan watermarking adalah algoritma PSO. Tujuan di optimasinya metode RDWT-DCT-SVD dan PSO akan secara acak menyisipkan citra watermark ke dalam citra masukan agar memperkuat ketahanan dan kualitas citra watermark sehingga dapat meningkatkan nilai PSNR.

\section{TINJAUAN PUSTAKA}

Pada bagian ini berisikan referensi-referensi yang digunakan sebagai bahan pembuatan penelitian ini.

\subsection{Digital Watermarking}

Digital watermarking dikembangkan sebagai jawaban untuk keabsahan pencipta atau pendistribusi yang memiliki suatu karya atau data digital. Digital Watermarking adalah penambahan atau pengurangan data dan informasi secara rahasia ke dalam sebuah sebuah citra atau media digital seperti citra, video, suara, dan lain-lain. Juga, ia memiliki turunan dari ilmu steganografi. Steganografi merupakan ilmu yang mengkaji tentang penyembunyian data. Dengan adanya teknik steganografi dapat mengalihkan perhatian dan keterbatasan indra manusia seperti indra pendengaran dan penglihatan, karena data akan dibuat sedemikian mirip dengan aslinya sehingga oleh manusia dianggap data atau media yang telah diwatermarking tersebut dianggap tidak ada perubahan sama sekali, akan tetapi jika media watermark tersebut dibedah dan polanya tahu, maka media tersebut dapat terlihat apakah terjadi perubahan atau penambahan data.

Teknik watermarking bekerja dengan cara mengubah sedikit informasi yang menunjukkan kepemilikan, tujuan, atau data lain pada media digital tanpa mempengaruhi kualitas dari data sebelumnya. Konsep steganografi juga dihubungkan selalu dengan sebutan invisible watermarking, yaitu tidak tampak seperti media data digital seperti text, video dan citra. Atau tidak kedengaran (untuk jenis audio) oleh pihak lain dengan menggunakan Panca Indera kita. Digital watermarking harus memenuhi beberapa kriteria penilaian yang nantinya akan diuji seperti robustness, imperceptibility, dan security. Imperceptibility berkaitan dengan keberadaan watermark yang tidak boleh tampak oleh mata manusia.
Encoding watermark citra merupakan proses penyisipan watermark ke dalam citra dapat disertai dengan memasukan kunci atau tidak memerlukan kunci (open keyless). Dengan adanya kunci maka dapat mencegah watermark dihapus oleh pihak yang tidak berhak. Kunci juga diperlukan agar watermark bisa diekstraksi oleh pihak yang sah dan oleh pihak yang mengetahu I pola kunci tersebut. Kunci ini untuk verifikasi untuk membuktikan status kepemilikan dari sebuah data yang telah ditanamkan watermark. Verifikasi watermark mempunyai dua subproses. Subproses ekstraksi watermark disebut juga decoding. Decoding adalah kebalikan fungsi dari encoding yang bertujuan mengekstraksi watermark dari dalam citra. Citra asal akan diikutsertakan dalam proses decoding (yang belum diberi watermark) untuk meningkatkan unjuk kerja yang lebih baik. Sub proses pembandingan ini bertujuan mengkomparasi antara data citra sebelum watermark dan sesudah ditanamkan watermark [6].

\subsection{Serangan Citra Watermarking}

Serangan terhadap citra ber-watermark umumnya memiliki tujuan untuk menghapus watermark yang disisipkan pada citra digital masukan tersebut. Serangan-serangan ini biasanya berhubungan dengan pengubahan citra, pengubahan ini dapat berupa filterisasi, rotasi, kompresi, dan lain-lain. Serangan dalam konsep citra dibagi menjadi dua yaitu serangan standar (standard attack) dan malicious attack. Malicious attack merupakan serangan dilakukan dengan tujuan untuk menghilangkan watermark. Pengujian pada citra yang akan diuji menggunakan serangan standard attack saja. Hal tersebut disebabkan karena dalam malicious attack umumnya pihak penyerang mencari algoritma penyisipan dan kuncinya. Serangam standar yang biasanya diuji antara lain sharpening, croping, salt peppers, bluring dan lain sebagainya [6].

\subsection{Redundant Discrete Wavelet Transform (RDWT)}

Berikan penjelasan tentang penelitian-penelitan yang menjadi dasar penelitian dari penulis.

Redundant Discrete Wavelet Transform (RDWT) secara umum sama seperti dengan DWT yaitu citra akan didekomposisi menjadi empat bagian yaitu LL, LH, HL, dan HH [7]. LL merupakan frekuensi rendah-rendah (low-low frequency), LH merupakan frekuensi rendah-tinggi (low-high frequency), HL adalah frekuensi tinggi-rendah (high-low frequency) dan $\mathrm{HH}$ adalah frekuensi tinggi-tinggi (high-high frequency) [8]. Perbedaannya adalah pada proses 
dekomposisi, RDWT menghilangkan proses downsampling [9].

Wavelet menggunakan energinya dalam ruang dan waktu sehingga cocok untuk menganalisis sinyal yang sifatnya sementara saja. Wavelet menganalisis digital dari sinyal gempa bumi. Menurut [10] Fungsi dari wavelet sudah semakin baik dengan adanya area sains terpisah yang berhubungan dengan analisis wavelet dan teori wavelet transformasi. Dengan ini wavelet mulai digunakan dalam filterasi, pengenalan citra, pemrosesan sintesis berbagai variasi kompresi dan sinyal. Transformasi wavelet adalah sebuah transformasi matematik yang digunakan untuk menganalisis sinyal bergerak untuk mendapatkan informasi spektrum frekuensi dan waktunya secara bersamaan.

Teknik ini menganalisis frekuensi dengan cara resolusi yang berbeda. Melalui operasi filterisasi, resolusi sinyal dapat merubah ukuran di didalam sinyal.

Kelebihan metode RDWT yaitu kompresi yang dihasilkan tidak mengganggu dibandingkan domain lain, dan distorsi yang disebabkan oleh domain dalam perbandingan kompresi tinggi dalam bit rate yang sama. Berikut adalah proses dekomposisi pada Gambar 1 [1]:
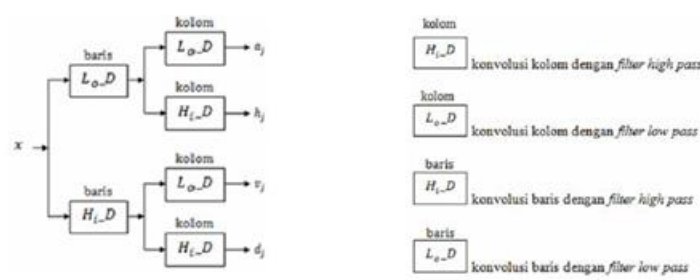

Gambar 1. Dekomposisi 2D RDWT

Rumus RDWT yang digunakan adalah:

$\operatorname{Img}[i]=\left(\operatorname{Img}[k] * L_{o}+\operatorname{Img}[k+1] * L_{1}\right)$

$\left.\operatorname{Img}[h+i]=\operatorname{Img}[k] * W_{o}+\operatorname{Img}[k+1] * W_{1}\right)$

$W_{o}=H i g h_{1}=0,707$

$W_{1}=\operatorname{High}_{2}=-0,707$

$L_{o}=L o w_{1}=0,707$

$L_{1}=L_{o w}=0,707$

Img = Array / matriks / menunjukan Img atau angga dalam suatu matriks

$k=$ koefisien yang menunjukan indeks pada matriks

$i=$ indeks yang yang dicari

Untuk mencari $\operatorname{Img}[k]$ menggunakan rumus:

$k=i \times 2$
Untuk mengetahui matriks mana bagian $\mathrm{L}$ atau $\mathrm{H}$ menggunakan rumus :

length $=$ indeks $/ 2$

Rumus IRDWT adalah:

$$
\begin{aligned}
& \operatorname{Img}[i]=\left(\operatorname{Img}[i] * W_{o}+\operatorname{Img}[i+h] * L_{o}\right) / L_{o} \\
& \operatorname{Img}[k+1]=\left(\operatorname{Img}[i] * W_{1}+\operatorname{Img}[i+h] * L_{1}\right) / L_{1}
\end{aligned}
$$

\subsection{Redundant Discrete Wavelet Transform (RDWT)}

Watermarking dapat dilakukan dengan berbagai metode, diantaranya menggunakan satu metode atau menggunakan hybrid. DCT merupakan metode yang dapat digabungkan dengan metode watermark lainnya agar dapat menghasilkan watermarking yang kuat sesuai dengan parameter penilaiannya. Watermarking akan dipetakan oleh DCT berdasarkan himpunan nilai sebanyak $n$ pada domain spasial menjadi domain frekuensial yang memiliki jumlah yang sama di himpunan lain yang telah ditransformasi tersebut. Transformasi himpunan lain tersebut menghasilkan bilang real.

Pada dasarnya DCT memiliki konsep mengganti koefisien citra DCT menjadi koefisen baru dengan menggunakan fungsi gelombang atau frukuensi cosinus diskrit. Pilihan frekuensi dapat mengganti pemilihan koefisien yang berbeda-beda.

Hasil citra watermark tidak akan mengalami perubahan yang signifikan, jika frekuensi yang dipilih adalah frekuensi tinggi. Maka koefisien yang dihasilkan akan memiliki nilai yang rendah, sehingga perubahan di dalam citra tidak terlihat perubahannya atau invisible change pabila dilihat oleh mata manusia [1].

Rumus DCT yang digunakan:

$$
\begin{aligned}
& C(x, y)= \\
& \propto(u) \sum_{x=0}^{n-1} \cos \frac{(3,14(2 * \text { index } \operatorname{col}+1) * \text { indexRow })}{2 * 2} \\
& * \\
& \propto(v) \sum_{y=0}^{1} \cos \frac{(3,14(2 * \text { indexCol }+1) * \text { indexRow })}{2 * 2} \\
& * \operatorname{Img}(x, y) \\
& \mathrm{C} \quad: \text { koefisien indeks ke-x } \\
& \propto \mathrm{u}, \propto \mathrm{v}: \text { faktor skalar } \mathrm{u} \text { (indeks baris) } \mathrm{v} \text { (indeks } \\
& \text { kolom) } \\
& \text { indexCol: ukuran kolom matriks } \\
& \text { indexRow: ukuran baris matriks }
\end{aligned}
$$


$\mathrm{x}, \mathrm{y} \quad$ : indeks yang sedang dicari nilainya

$\alpha(u)=\left\{\begin{array}{l}1 / \sqrt{ } n, \text { jika } u=0 \\ \sqrt{ } 2 / n, \text { jika } u>0\end{array}\right.$

$\alpha(v)=\left\{\begin{array}{l}1 / \sqrt{ } \mathrm{n}, \text { jika } v=0 \\ \sqrt{ } 2 / \mathrm{n}, \text { jika } v>0\end{array}\right.$

$\mathrm{n}=$ panjang length

$\operatorname{Img}(\mathrm{x}, \mathrm{y})=[$ value -128$]$

Rumus IDCT:

$$
\begin{aligned}
& C(u, v) \\
& =\sum_{x=0}^{n-1} \sum_{y=0}^{n-1} \alpha(u) \cdot \alpha(v) \cdot \operatorname{Img}(x, y) \\
& =\cos \frac{(\pi(2 * \text { indexCol }+1) \text { indexRow })}{2 n} \\
& \cos \frac{(\pi(2 * \text { indexCol }+1) \text { indexRow })}{2 n}
\end{aligned}
$$

\subsection{Discrete Cosin Transform (DCT)}

Singular Value Decomposition adalah sebuah faktorisasi dari matriks bilangan nyata atau kompleks yang berbentuk persegi. SVD dapat mendiagonalkan matriks dengan teknik analisis numerik yang dimasukan ke dalam rumus SVD. Jadi jika diagonal matriks tersebut dikalikan maka akan menghasilkan nilai yang sama. Teknik ini kini digunakan dalam menyisipkan watermark ke dalam citra.

Jika sebuah citra yang akan diberi watermark memiliki ukuran MxN. Maka citra tersebut dapat dipresentasikan ke dalam sebuah matriks bukan bernilai nol dan dibuat menjadi persamaan [2]:

$$
C=U S V^{T}
$$

Keterangan :

$$
\begin{array}{ll}
\mathrm{C} & \text { : matriks MxN dari ukuran citra } \\
\mathrm{U} & \text { : ortoghonal matriks } \mathrm{MxM} \\
\mathrm{S} & \text { : singular matriks } \mathrm{MxN} \\
\mathrm{V} & \text { : orthoghonal matriks } \mathrm{NxN}
\end{array}
$$

\subsection{Algoritma Particle Swarm Optimization (PSO)}

Algoritma PSO disebut sebagai algoritma metaheuristik, karena dapat memiliki kemampuan untuk mencari solusi terbaik yang mampu menyebarkan partikel atau komponen secara acak dan dapat berpindah posisi dengan dinamik hingga ia dapat menemukan hasil solusi yang optimal. Setiap partikel akan memberi informasi atau posisi terbaik kepada partikel lain berdasarkan hasil yang informasi yang diperoleh dengan cara menyesuaikan posisi dan kecepatannya.

Kelebihan algoritma PSO yaitu mudah diimplemestasikan dan parameter yang dibutuhkan hanya sedikit, tidak memiliki evolusi pada operasinya misalnya seperti mutasi pada algortima genetika yang memiliki banyak komputasi, Secara konsep mutasi, PSO lebih efesien disbanding algoritma yang lain karena memiliki sedikit komputasi [11].

Adapun langkah penerapan PSO untuk mendapatkan embed $\mathrm{S}$ baru dengan rumus $\mathrm{S} \_\mathrm{H}=\mathrm{S} \_$Host $+\Phi * \mathrm{P}$ dari proses SVD adalah sebagai berikut:

1. Menentukan Coofisien Acceleration

$\sum($ epsilon $)=0,025$

$\mathrm{C}=1,5$

$\mathrm{W}=0,7$

$\mathrm{V}=$ nilai random

Gbest $=255$

$\mathrm{R}=$ nilai random

$\Phi=$ matriks generate random

Partikel PSO yaitu:

$V_{(k+1)}=W \cdot V_{k}+\left(C * R\left(G_{\text {best }}-\Phi_{(i, j)}\right)\right)$

$X_{(k+1)=} \Phi_{(k)}+V_{(k)}$

2. Mencari nilai fitnes PSO

Fitness awal $=\sum_{m=0}^{m-1} \sum_{n=0}^{n-1} 1-\frac{\operatorname{ori}(m, n)}{\operatorname{embed}(m, n)}$

Ori= nilai $\mathrm{S}$ dari citra awal

Embed $=\mathrm{S}+$ generate number $* \mathrm{P}$

Jika nilai embed lebih dari 255 maka $=255$

3. Generate random sebanyak mxn menggunakan multivlicative.

$Z_{n}=Z_{n-1} C \bmod M$

Dimana:

$Z_{0}=100$

$\mathrm{C}=127$

$\mathrm{M}=268$

$\mathrm{U}=\sum \frac{Z}{m} * 255$

4. Cari nilai fitnes dari generate random yang baru sebanyak iterasi n yang mendekati epsilon $=0,025$

5. Jika telah mendekati atau sama dengan nilai epsilon yang ditentukan maka langsung didekomposisi atau penggabungan citra masukan dengan citra watermark dengan menggunakan rumus:

$$
S_{H}=S_{\text {Host }}+\Phi * P
$$

$S_{H}=\mathrm{S}$ baru atau nilai hasil dekomposisi

$S_{\text {Host }}=$ Nilai SVD S dari citra masukan

$\Phi=$ Nilai generate random dengan iterasi mendekati epsilon 
$P=$ Nilai perkalian $\mathrm{U}$ dan $\mathrm{S}$ dari citra watermark.

\section{RANCANGAN SISTEM DAN APLIKASI}

Metode penelitian yang digunakan pada penelitian ini yaitu metode eksperimen. Dalam pengumpulan data dengan cara mengumpulkan jurnal-jurnal dan buku yang terkait dengan penelitian ini serta mencari bukubuku untuk mendalami materi mengenai watermarking dengan menggunakan algoritma PSO dengan kombinasi teknik RDWT-DCT-SVD. Metode pengembangan sistemnya menggunakan waterfall. Berikut adalah langkah penelitian:

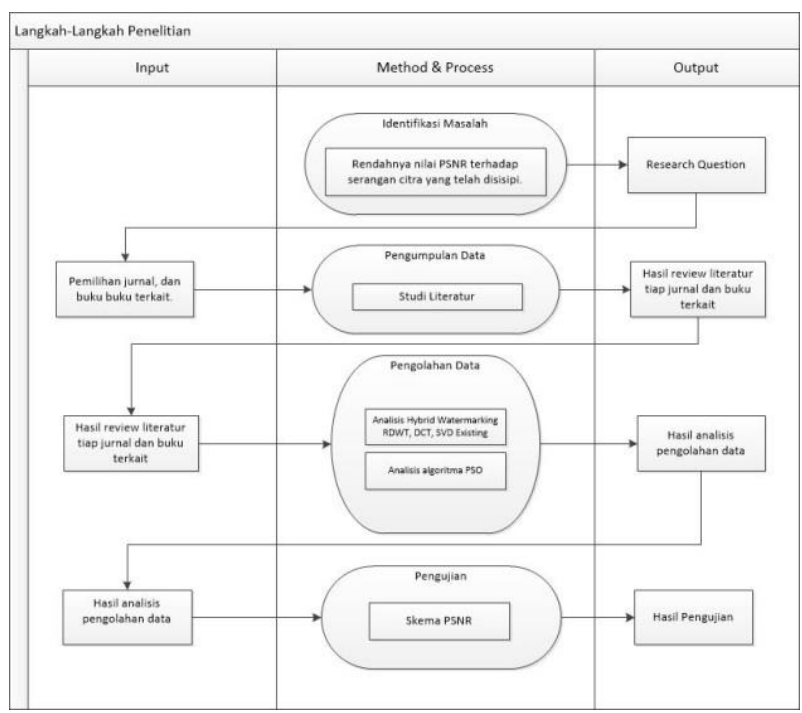

Gambar 2. Langkah penelitian

\section{HASIL DAN PEMBAHASAN}

Berikut adalah gambaran usulan detail metode hybrid yang digunakan dalam proses watermarking, di mana setiap metode memiliki transformasi yang berbedabeda untuk menghasilkan hybrid invisble watermarking ini, dapat dilihat pada Gambar 3.

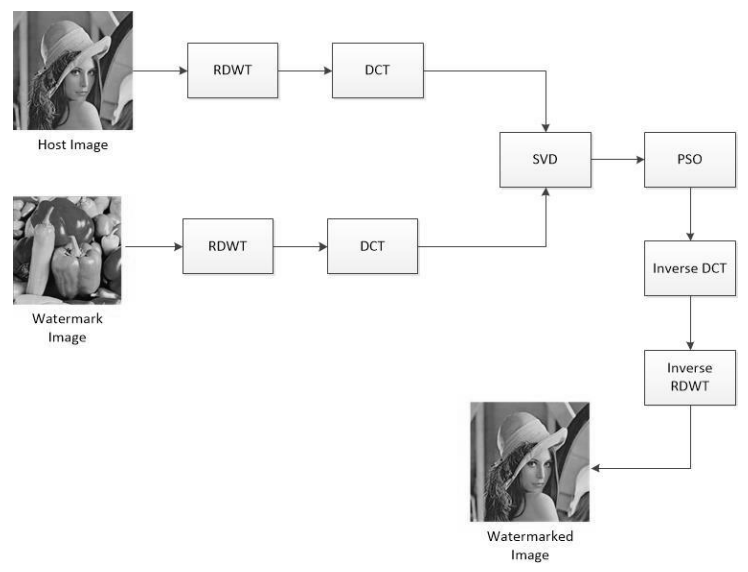

Gambar 3. Proses usulan Hybrid Watermark
Pada Gambar 3, citra masukan dan citra watermark akan diproses untuk menghasilkan invisible watermark dengan langkah berikut:

1. Citra masukan dan citra watermark akan ditransformasi ke dalam metode RDWT. Transformasi RDWT akan mendekomposisi citra menjadi 4 bagian frekuensi yaitu LL (low-low), HL (high-low), LH (low-high) dan HH (highhigh).

2. Setelah proses dekomposisi 4 frekuensi, proses selanjutnya adalah transformasi DCT. Proses DCT ini akan diterapkan pada bagian frekuensi LL. Karena bagian LL dari RDWT mempunyai koefisien positif.

3. Langkah selanjutnya adalah proses SVD dimana citra yang telah ditransformasi DCT akan dibagi pixelnya menjadi tiga bagian, yaitu merubah menjadi nilai singular. Nilai singular SVD citra masukan dan citra watermark akan digabungkan proses algoritma PSO yang akan membuat generate random pixel dan nilai fitnes untuk mengacak citra watermark untuk diletakkan ke dalam citra masukan.

4. Menerapkan inverse DCT untuk mengembalikan ukuran matriks yang telah ditransformasi DCT.

5. Menerapkan inverse RDWT untuk mengembalikan ukuran matriks yang telah ditransformasi RDWT.

\subsection{Hasil Pengujian Citra}

Citra awal yang dapat diinputkan dapat berformat .jpg, .tif, atau .png. Citra yang akan diubah kedalam bentuk matriks adalah citra Lena dengan ukuran 256 x 256 pixel. Citra Lena akan diambil nilai setiap range warnanya yaitu R (red), G (green), dan B (blue) yang nantinya diproses setiap pixelnya untuk ditransformasi ke dalam koefisien masing-masing metode. Data citra yang diuji dan dikomparasi dengan penelitian sebelumnya menggunakan citra Lena sebagai citra masukan, corp.jpg dan Reduce.Jpeg sebagai citra watermark.
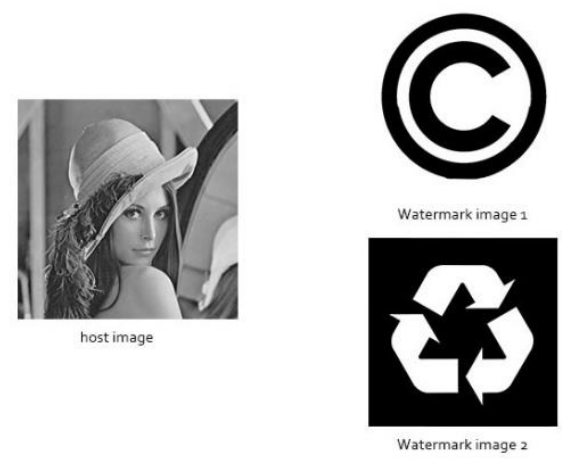

Gambar 4. Data Citra Masukan dan Watermark 
Berikut adalah hasil implementasi dan pengujian menggunakan data Lena.Jpg sebagai citra masukan dan citra Corp.Jpg sebagai citra watermark, pada Tabel 1:

Tabel 1. Hasil Pengujian Corp.Jpg Watermark

\begin{tabular}{|c|c|c|c|}
\hline Attack & Rttacked Image & $\begin{array}{c}\text { Extracted } \\
\text { Watermark }\end{array}$ & Result \\
\hline Rotate 75 & $48,34 \mathrm{~dB}$ \\
\hline $\begin{array}{c}\text { Contrast } \\
\text { +50 }\end{array}$ & & \\
\hline Histogram & & \\
\hline Silter $7 \times 7$ & & \\
\hline
\end{tabular}

Dari hasil pengujian dari citra Lena.Jpg dan citra Corp.Jpg didapatkan hasil PSNR yang cukup baik dengan rata-rata diatas $50 \mathrm{~dB}$. Hasil ekstraksi dari berbagai macam serangan ini juga sudah baik, namun pada serangan rotate dan median filter tampak citra watermark mengalami sedikit kerusakan akan tetapi citra Corp.Jpg masih terlihat dengan jelas dan masih dapat teridentifikasi.

Berikut hasil pengujian dari berbagai macam serangan dengan citra lena.Jpg dan Reduce.Jpg:
Tabel 2. Hasil Pengujian Corp.Jpg Watermark

\begin{tabular}{|c|c|c|c|}
\hline Attack & Attacked Image & $\begin{array}{c}\text { Extracted } \\
\text { Watermark }\end{array}$ & Result \\
\hline Rotate 75 & & \\
\hline $\begin{array}{c}\text { Contrast } \\
\text { +50 }\end{array}$ & & \\
\hline Histogram \\
Milter $7 \times 7$
\end{tabular}

Dari hasil pengujian dari citra Lena.Jpg dan citra Reduce.Jpg didapatkan hasil PSNR yang cukup baik dengan rata-rata diatas $50 \mathrm{~dB}$. Hasil ekstraksi dari berbagai macam serangan ini juga sudah baik, namun pada median filter tampak citra watermark mengalami sedikit kerusakan akan tetapi citra Corp.Jpg masih terlihat dengan jelas dan masih dapat teridentifikasi.

Penelitian ini juga mencoba beberapa citra standar image processing yang diuji untuk hybrid watermarking diantaranya citra Lena, Bird, Cameraman, dan Ship. Kemudian untuk citra watermark-nya menggunakan Reduce dan Corp. Masing-masing memiliki standar nilai PSNR dan hasil ekstraksi citra yang berbeda. Untuk melihat nilai PSNR dari citra-citra tersebut dapat dilihat pada Tabel 3. 
Tabel 3 Implementasi Standar Image Processing Watermark

\begin{tabular}{|l|c|c|c|c|c|}
\hline Serangan & Lena & Bird & Cameraman & Ship & Babon \\
\hline $\begin{array}{l}\text { Contrast } \\
+50\end{array}$ & $\begin{array}{c}59,00 \\
\mathrm{~dB}\end{array}$ & $\begin{array}{c}58,61 \\
\mathrm{~dB}\end{array}$ & $57,82 \mathrm{~dB}$ & $\begin{array}{c}58,39 \\
\mathrm{~dB}\end{array}$ & $\begin{array}{c}59,32 \\
\mathrm{~dB}\end{array}$ \\
\hline Histogram & $\begin{array}{c}61,60 \\
\mathrm{~dB}\end{array}$ & $\begin{array}{c}61,3 \\
\mathrm{~dB}\end{array}$ & $58,24 \mathrm{~dB}$ & $\begin{array}{c}61,3 \\
\mathrm{~dB}\end{array}$ & $\begin{array}{c}57,22 \\
\mathrm{~dB}\end{array}$ \\
\hline $\begin{array}{l}\text { Median } \\
\text { filter } 7 \mathrm{x} 7\end{array}$ & $\begin{array}{c}59,7 \\
\mathrm{~dB}\end{array}$ & $\begin{array}{c}61,95 \\
\mathrm{~dB}\end{array}$ & $58,74 \mathrm{~dB}$ & $\begin{array}{c}61,63 \\
\mathrm{~dB}\end{array}$ & $\begin{array}{c}60,71 \\
\mathrm{~dB}\end{array}$ \\
\hline Rotate75 & $\begin{array}{c}49,4 \\
\mathrm{~dB}\end{array}$ & $\begin{array}{c}50,2 \\
\mathrm{~dB}\end{array}$ & $49,58 \mathrm{~dB}$ & $\begin{array}{c}50,72 \\
\mathrm{~dB}\end{array}$ & $\begin{array}{c}50,81 \\
\mathrm{~dB}\end{array}$ \\
\hline $\begin{array}{l}\text { Salt pepper } \\
(0,01)\end{array}$ & $\begin{array}{c}60,99 \\
\mathrm{~dB}\end{array}$ & $\begin{array}{c}61,65 \\
\mathrm{~dB}\end{array}$ & $59,56 \mathrm{~dB}$ & $\begin{array}{c}61,65 \\
\mathrm{~dB}\end{array}$ & $\begin{array}{c}62,36 \\
\mathrm{~dB}\end{array}$ \\
\hline Sharpening & $\begin{array}{c}62,83 \\
\mathrm{~dB}\end{array}$ & $\begin{array}{c}67,96 \\
\mathrm{~dB}\end{array}$ & $62,42 \mathrm{~dB}$ & $\begin{array}{c}63,98 \\
\mathrm{~dB}\end{array}$ & $\begin{array}{c}66,00 \\
\mathrm{~dB}\end{array}$ \\
& $\begin{array}{c} \\
\end{array}$ & & & & \\
\hline
\end{tabular}

Dilihat dari Tabel 3 bahwa masing-masing citra memiliki nilai PSNR yang berbeda. Akan tetapi range nilai dari serangan yang sama nilai PSNRnya tidak terlalu signifikan jauh beda. Berikut adalah hasil ratarata PSNR berdasarkan serangannya, dapat dilihat pada Tabel 4:

Tabel 4 Rata-rata PSNR Setiap Serangan Citra

\begin{tabular}{|l|c|}
\hline \multicolumn{1}{|c|}{ Serangan } & Average PSNR \\
\hline Contrast 50 & $58.628 \mathrm{~dB}$ \\
\hline Histogram & $59.932 \mathrm{~dB}$ \\
\hline Median filter $7 \times 7$ & $60.546 \mathrm{~dB}$ \\
\hline Rotate 75 & $50.142 \mathrm{~dB}$ \\
\hline Salt pepper $(0,01)$ & $61.242 \mathrm{~dB}$ \\
\hline Sharpening & $64.638 \mathrm{~dB}$ \\
\hline
\end{tabular}

Hasil dari Tabel 4 nilai PSNR yang didapat dari masing-masing serangan tidak jauh signifikan berbeda dan memiliki PSNR yang baik dengan hasil di atas 50 $\mathrm{dB}$.

Nilai PSNR didapat digunakan ketika citra watermark telah berhasil disisipi dan telah dilakukan seranganserangan. Perhitungan nilai PSNR menggunakan rumus seperti berikut:

$$
P S N R=10 \log _{10}\left[\frac{\mathrm{Cmax}^{2}}{M S E}\right]
$$

\subsection{Komparasi Hasil PSNR}

Penelitian ini mengkomparasi antara metode hybrid RDWT-DCT-SVD dengan RDWT-DCT-SVD-PSO menggunakan citra yang sama dan parameter serangan yang sama juga. Komparasi yang digunakan adalah ketika citra watermark telah berhasil disisipi dan diserang oleh berbagai macam serangan. Berikut adalah hasil komparasi antara metode RDWT-DCTSVD dengan metode hybrid watermarking yang diusulkan yaitu RDWT-DCT-SVD-PSO, dapat dilihat pada Tabel 5:

Tabel 5 Hasil Komparasi Nilai PSNR

\begin{tabular}{|l|l|l|}
\hline & \multicolumn{1}{|c|}{$\begin{array}{c}\text { RDWT DCT } \\
\text { SVD }\end{array}$} & $\begin{array}{c}\text { RDW DCT SVD } \\
\text { PSO }\end{array}$ \\
\hline Contrast +50 & 14,417 & $\mathbf{5 9 , 0 0}$ \\
\hline Histogram & 21,041 & $\mathbf{6 1 , 7 2}$ \\
\hline Median filter 7x7 & 27,53 & $\mathbf{5 9 , 8 2}$ \\
\hline Rotate 75 & 8,17 & $\mathbf{4 8 , 9}$ \\
\hline Salt pepper 0,01 & 14,888 & $\mathbf{6 0 , 9 6}$ \\
\hline Sharpening & 24,05 & $\mathbf{6 2 , 8 3}$ \\
\hline
\end{tabular}

Tabel tersebut jika dijadikan sebuah grafik perbandingan nilai PSNR antara metode sebelumnya dan metode yang diusulkan adalah seperti pada Gambar 5

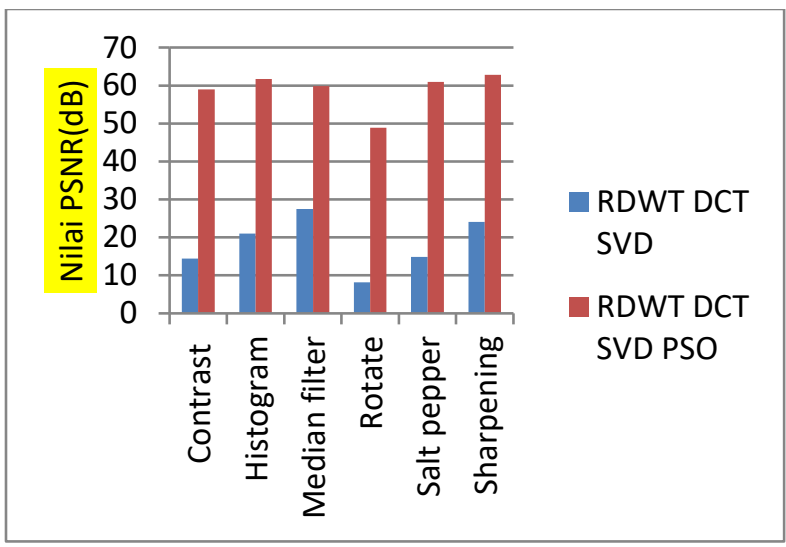

Gambar 5 Grafik Perbandingan Nilai PSNR

\subsection{Kesimpulan Pengujian}

Pada kesimpulan pengujian ini menjelaskan hybrid watermarking RDWT-DCT-SVD dan PSO tentang cara kerja, hasil penelitian, dan komparasi dengan penelitian lain, diantaranya adalah sebagai berikut:

1. Dengan adanya penambahan algoritma PSO pada hybrid watermarking RDWT-DCT-SVD cara menyisipkan watermark secara invisible, lalu dengan acak menyisipkan watermark tersebut ke dalam citra masukan. Karena polanya acak dan berganti, metode PSO ini tidak mudah ditebak pola penyisipannya atau tidak mudah dihilangkan. Penyisipan PSO mengoptimasi pixel dari citra masukan, watermark dan generate random pixel yang sudah dioptimalkan sehingga polanya acak dan berganti, tidak mudah untuk ditebak pola penyisipannya juga tidak mudah dihilangkan.

2. Hasil pengujian menggunakan 6 serangan yaitu contrast, histogram, median filter, rotasi, salt 
peppers, dan sharpening rata-rata bernilai $50 \mathrm{~dB}$ yang dapat diartikan bahwa kualitas citra masukan dan watermark setelah bergabung sangat bagus dan memiliki imperceptibility dari keberadaan citra watermark cukup tinggi.

a.Serangan contrast memiliki ekstraksi yang baik, tidak megubah bentuk dari citra watermark.

b. Serangan histogram memiliki ekstraksi yang baik, tidak megubah bentuk dari citra watermark.

c.Serangan median filter pada ekstraksi hanya citra Lena dan Cameraman memiliki sedikit kerusakan akan tetapi bentuk dari watermark masih teridentifikasi.

d. Serangan rotasi memiliki ekstraksi yang baik, tidak megubah bentuk dari citra watermark.

e.Serangan salt peppers pada ekstraksi hanya citra cameraman yang masih memiliki filter salt peppers di citra watermark-nya, akan tetapi bentuk atau logo watermark-nya masih dapat teridentifikasi.

f. Serangan sharpening memiliki ekstraksi yang baik, tidak megubah bentuk dari citra watermark.

3. Pada hasil komparasi antara RDWT-DCT-SVD dengan metode yang diusulkan hybrid watermarking RDWT-DCT-SVD dan PSO menjelaskan bahwa metode yang diusulkan dapat meningkatkan nilai PSNR ketika serangan. Peningkatan hasil PSNR ini cukup beda tinggi yang signifikan karena ada penambahan metode PSO pada proses penyisipan watermark-nya. Penelitian dari (Gaur \& Srivastava, 2017) yang menambahkan metode RDWT-DCT-SVD dengan arnold transform jika dibandingkan dengan hasil PSNR penelitian ini tidak cukup jauh nilainya, jadi dengan penambahan metode PSO pada proses hybrid watermarking ini memang tepat diterapkan karena berhasil meningkatkan nilai PSNR ketika citra mengalami serangan.

\section{KESIMPULAN}

Setelah melakukan analisis, perancangan, implementasi dan pengujian dan komparasi hybrid watermarking, maka dapat disimpulkan bahwa hybrid watermark menggunakan RDWT-DCT-SVD dan optimasi PSO mampu menghasilkan kualitas citra secara invisible yang bagus serta tidak terlalu merusak citra saat penyisipan maupun ekstraksi. Performansi PSO pada hybrid invisible dapat dilihat dari penjelasan sebelumnya mampu menyisipkan citra watermark secara acak, sehingga tidak dapat diserang dengan mudah dan menghasilkan imperceptibility yang baik. Kemudian hasil PSNR yang dihasilkan dengan rata-rata $50 \mathrm{~dB}$. Hybrid watermarking RDWTDCT-SVD dan optimasi PSO yang diusulkan ini memiliki hasil yang signifikan lebih tinggi daripada hybrid watermarking sebelumnya.

Berdasarkan hasil penelitian hybrid watermarking RDWT-DCT-SVD dan optimasi PSO ini diusulkan beberapa saran yaitu:

1. Perlu dipertimbangkan untuk menambahkan metode untuk menghasilkan hasil citra ekstraksi lebih baik dan meningkatnya nilai PSNR.

2. Gunakan algoritma genetika untuk komparasi optimasi hybrid watermarking RDWT-DCTSVD.

\section{Ucapan Terima Kasih}

Ucapan terima kasih dan judul Referensi (DaftarPustaka) menggunakan justified, dicetak tebal, dengan huruf kapital tetapi tidak memiliki angka. Teks di bawah ini berlanjut seperti Tuliskan ucapan terima kasih dengan bahasa baku, misalnya, "Penulis C.N. (inisial nama mahasiswa) mengucapkan terima kasih kepada Direktorat Pendidikan Tinggi, Departemen Pendidikan dan Kebudayaan Republik Indonesia yang telah memberikan dukungan finansial melalui Beasiswa Bidik Misi tahun 2012-2016". Penulis juga diperkenankan menyampaikan ucapan terima kasih kepada sponsor penyedia dana penelitian.

\section{DAFTAR PUSTAKA}

[1] A. Bajaj, "Robust And Reversible Digital Image Watermarking Technique Based On RDWTDCT-SVD,” IEEE Int. Conf., pp. 1-5, 2014.

[2] S. Gaur and V. K. Srivastava, "A hybrid RDWTDCT and SVD based digital image watermarking scheme using Arnold transform," 2017 4th Int. Conf. Signal Process. Integr. Networks, SPIN 2017, pp. 399-404, 2017.

[3] P. Singh, "Robust Digital Color Image Watermarking in Hybrid Domain," Int. J. IJLTEM, vol. 1, no. 1, pp. 33-41, 2016.

[4] K. Loukhaoukha, M. Nabti, and K. Zebbiche, "A robust SVD-based image watermarking using a multi-objective particle," Opto-Electronics Rev., vol. 18, pp. 45-54, 2013.

[5] K. Kuppusamy and K. Thamodaran, "Optimized Hybrid Image Security Scheme for Copyright Protection, Authentication and Confidentiality Using PSO," vol. 9, no. 6, pp. 129-146, 2013. 
[6] A. O. Adesina, H. O. Nyongesa, and K. K. Agbele, "Digital Watermarking: A State-of-theArt Review," IST-Africa 2010 Conf. Proc., pp. $1-8,2010$.

[7] Z. Kricha, A. Kricha, and A. Sakly, "A Robust Watermarking Scheme Based on the Mean Modulation of DWT Coefficients," Secur. Commun. Networks, vol. 2018, 2018.

[8] S. Gaur and V. Kumar, "A RDWT and BlockSVD based Dual Watermarking Scheme for Digital Images," Int. J. Adv. Comput. Sci. Appl., vol. 8, no. 4, pp. 211-219, 2017.

[9] T. H. Rassem, N. M. Makbol, and B. E. Khoo, "Performance evaluation of RDWT-SVD and DWT-SVD watermarking schemes," AIP Conf. Proc., vol. 1774, no. October 2016, 2016.

[10] Y. Han, X. Cui, Y. Zhang, and T. Xu, "Research on Color Watermarking Algorithm Based on RDWT- SVD,” vol. 5, no. 2, pp. 149-156, 2017.

[11] A. I. Hammouri, B. Alrifai, and H. Al-hiary, "An Intelligent Watermarking Approach Based Particle Swarm Optimization in Discrete Wavelet Domain," IJCSI Int. J., vol. 10, no. 2, pp. 330338, 2013. 